\title{
Cuidadores de pacientes en diálisis peritoneal: experiencia de participar en un programa de habilidad de cuidado
}

\author{
Daniela López León ${ }^{1}$, Lorena Rodríguez Calderón ${ }^{1}$, Sonia Carreño Moreno², Ivonne Cuenca ${ }^{3}$, Lorena Chapa- \\ rro Díaz ${ }^{4}$
}

${ }^{1}$ Enfermeras vinculadas al Grupo de Cuidado de Enfermería al Paciente Crónico. ${ }^{2}$ Profesora Auxiliar. ${ }^{4}$ Profesora Asociada. Facultad de Enfermería Universidad Nacional de Colombia. ${ }^{3}$ Enfermera especialista. Clínicas renales RTS SAS. Colombia

\section{Resumen}

Los cuidadores de pacientes en terapia de diálisis peritoneal requieren fortalecer su habilidad de cuidado.

Objetivo: Describir la experiencia del cuidador familiar que cuida a personas en diálisis peritoneal que asisten al programa "Cuidando a los cuidadores" ${ }^{\odot}$ Versión institucional".

Metodología: Estudio cualitativo de tipo descriptivo, realizado en el primer semestre de 2015, con una muestra conformada por 277 relatos de cuidadores familiares de personas en diálisis peritoneal que asistieron al programa "Cuidando a los Cuidadores ${ }^{\odot}$ versión institucional". Para el análisis de los datos se utilizó el programa Atlas Ti versión 6.0; construyendo una taxonomía inductiva de los hallazgos, reduciendo los códigos descriptores a nominales y estos a su vez a categorías de análisis, mediante técnicas de análisis de contenido. Se realizó proceso de consentimiento informado.

Resultados: Dentro de las características de los cuidadores se encontró que en su mayoría son mujeres en edad productiva, que son las madres, hijas o esposas del familiar a quien cuidan. Se construyeron 7 categorías de análisis: nuevos conocimientos, interacción con otros, apoyo, descansar, bienestar, oportunidad de mejorar, nueva perspectiva.

\section{Correspondencia:}

Sonia Carreño Moreno

Facultad de Enfermería. Universidad Nacional de Colombia Ciudad Universitaria, Carrera 30

Calle 45-03, Torre de enfermería. Of. 901

Código Postal 111321. Bogotá D.C. Colombia

E-mail: spcarrenom@unal.edu.co

E-mail:gcronico_febog@unal.edu.co
Conclusiónes: La experiencia de participar en el programa Cuidando a los Cuidadores ${ }^{\odot}$ versión institucional", es una experiencia que va desde adquirir nuevos conocimientos hasta tener una nueva perspectiva como cuidador.

PALABRAS CLAVE

- CUIDADORES

- DIÁLISIS PERITONEAL

- HABILIDAD

- ENFERMERÍA

Caregivers of peritoneal dialysis patients: experience of participating in a skilled care program

\section{Abstract}

The caregivers of patients on peritoneal dialysis therapy need to strengthen their ability to care.

Goal: To describe the experience of the family caregiver who cares for people in peritoneal dialysis that attending the program "Caring for the caregivers" ${ }^{\prime \odot}$ Institutional Version".

Methodology: Qualitative descriptive study, conducted in the first half of 2015, with a sample consisting of 277 stories of family caregivers of peritoneal dialysis who attended the program "Caring for the Caregivers ${ }^{\odot}$ institutional version". To analyze the data the Atlas Ti program version 6.0 was used; an inductive findings taxonomy was built, reducing the nominal codes and descriptors to turn to these categories of analysis, was used content analysis techniques. Informed consent process was performed. 
Results: Among the characteristics of caregivers found that most of them are of working age women who are mothers, daughters or wives who take care of the family. 7 categories of analysis were constructed: New knowledge, interaction with others, support, rest, welfare, opportunity to improve and new perspective.

Conclusions: : The experience of participating in the program "Caring for the Caregivers ${ }^{\odot}$ institutional version" is an experience that goes from acquiring new knowledge to gain new perspective as a caregiver.

\section{KEYWORDS}

- CAREGIVERS

- PERITONEAL DIALYSIS

- ABILITY

- NURSING

\section{Introducción}

La enfermedad renal crónica (ERC) se ha convertido en un problema de salud pública importante, pues es una de las enfermedades con alta prevalencia a nivel mundial, aumentando en un $6.8 \%$ anualmente ${ }^{1}$.

Los tratamientos a los que son sometidos los pacientes con $E R C^{2}$, son de carácter invasivo y altamente demandantes, estos requieren cuidados domiciliarios que precisan de un cuidador que se haga cargo de estos ${ }^{3}$. Dentro de los cuidados que asumirá el cuidador se encuentran los cambios de la solución para dializar, registro del balance de líquidos, peso diario del paciente, alimentación adecuada, vigilancia del catéter peritoneal al realizar el recambio, asistencia a los controles de medicina y enfermería, entre otros ${ }^{4}$. El cuidador familiar además de realizar cuidados instrumentales, también tendrá el "papel amortiguador de todas las tensiones que se van generando en el proceso de la enfermedad ${ }^{\prime \prime}$, lidiando así, con la carga emocional de la persona a quien cuida y del círculo familiar y social que lo rodea.

El compromiso, tiempo y habilidades que los cuidadores dedican a su laborb, le generan un cambio radical en el estilo y calidad de vida que puede expresarse como en un estrés permanente, alteración en la ejecución habitual del rol, dificultades en interacciones sociales, falta de actividad y dispersión, entre otros ${ }^{7}$.
En Colombia, se ha desarrollado el programa "Cuidando a los cuidadores $^{\odot}$ ", bajo los lineamientos conceptuales de Ngozy Nkongo y con el objetivo de fortalecer la habilidad de cuidado de cuidadores familiares de personas con enfermedad crónica ${ }^{8}$.

El objetivo de este estudio fue Describir la experiencia del cuidador familiar que cuida a personas en diálisis peritoneal que asisten al programa "Cuidando a los cuidadores" ${ }^{\circ}$ Versión institucional".

\section{Metodología}

Estudio cualitativo de tipo descriptivo, realizado en el primer semestre de 2015, en el marco del Programa para la Disminución de la carga de la enfermedad crónica no transmisible en Colombia. Proyecto financiado por Colciencia, Contrato número 366 de 2011 y del cual el Grupo de Investigación de Cuidado de Enfermería al Paciente Crónico es investigador principal.

La muestra estuvo constituida por relatos de 277 cuidadores familiares de personas en diálisis peritoneal que asistieron al programa "Cuidando a los Cuidadores $^{\odot}$ versión institucional". Al finalizar la participación de los cuidadores en el programa, se les pidió que relataran su experiencia a través de un escrito. Este contestaba cuatro sencillas preguntas: ¿Qué fue lo que más le gustó? ¿Qué no le gustó?, ¿Qué fue lo que más le sirvió? y sugerencias.

Los cuidadores participaron de forma voluntaria en el estudio, se les realizó el proceso de consentimiento informado. El estudio cumplió con la legislación vigente para la investigación con seres humanos siendo este un estudio con riesgo mínimo, ${ }^{10}$.

Los relatos de los cuidadores fueron transcritos textualmente en documentos en formato Word, añadidos y analizados en el programa Atlas Ti versión $6.0^{11}$ bajo la licencia de la Universidad Nacional de Colombia. El análisis cualitativo de los datos se desarrolló construyendo una taxonomía inductiva de los hallazgos, reduciendo los códigos descriptores a nominales y estos a su vez a categorías de análisis, mediante técnicas de análisis de contenido ${ }^{12,13}$.

El proceso de análisis de los datos fue desarrollado por tres investigadores y sometido a un proceso de discusión y crítica por parte de expertos del grupo de Cuidado de Enfermería al Paciente Crónico de la Universidad Nacional de Colombia. 


\section{Resultados}

\section{Características de los cuidadores}

En la tabla 1 se presentan las características de los cuidadores.

Tabla 1. Características de los cuidadores

\begin{tabular}{|c|c|c|c|}
\hline Ítem & Categoría & Número & Porcentaje \\
\hline \multirow[t]{2}{*}{ Género } & Femenino & 241 & 87,0 \\
\hline & Masculino & 36 & 13,0 \\
\hline \multirow[t]{4}{*}{ Edad } & Desviación estándar & 14,5321 & \\
\hline & Mínima & 61,0 & \\
\hline & Máxima & 16,0 & \\
\hline & Media & 48.6 & \\
\hline \multirow[t]{8}{*}{ Escolaridad } & Bachillerato Completo & 77,0 & 27,8 \\
\hline & Bachillerato Incompleto & 62,0 & 22,4 \\
\hline & Postgrados & 6 & 2,2 \\
\hline & Primaria Completa & 31 & 11,2 \\
\hline & Primaria Incompleta & 21 & 7,6 \\
\hline & Técnico & 50 & 18,1 \\
\hline & Universidad Completa & 21 & 7,6 \\
\hline & Universidad Incompleta & 9 & 3,2 \\
\hline \multirow[t]{5}{*}{ Estado civil } & Casado(a) & 123 & 44,4 \\
\hline & Separado(a) & 25 & 9,0 \\
\hline & Soltero(a) & 58 & 20,9 \\
\hline & Unión Libre & 55 & 19,9 \\
\hline & Viudo(a) & 16 & 5,8 \\
\hline \multirow[t]{5}{*}{ Ocupación } & Empleado & 36 & 13,0 \\
\hline & Estudiante & 13 & 4,7 \\
\hline & Hogar & 153 & 55,2 \\
\hline & Otra. ¿Cuál? & 8 & 2,9 \\
\hline & Trabajo Independiente & 67 & 24,2 \\
\hline \multirow[t]{5}{*}{ Estrato } & 1,0 & 24 & 8,7 \\
\hline & 2,0 & 121 & 43,7 \\
\hline & 3,0 & 109 & 39,4 \\
\hline & 4,0 & 20 & 7,2 \\
\hline & 5,0 & 3 & 1,1 \\
\hline \multirow[t]{2}{*}{$\begin{array}{l}\text { ¿Cuida a la persona } \\
\text { a su cargo } \\
\text { desde el momento } \\
\text { de su diagnóstico? }\end{array}$} & No & 32 & 11,6 \\
\hline & Si & 245 & 88,4 \\
\hline \multirow[t]{2}{*}{ Único cuidador } & No & 109 & 39,4 \\
\hline & Si & 168 & 60,6 \\
\hline
\end{tabular}

Fuente: Datos del estudio 2015.

\section{Categorías de análisis}

Como resultados del análisis cualitativo de los datos surgieron siete categorías de análisis que se muestran en la tabla 2.

Tabla 2. Códigos y categorías que emergieron

\begin{tabular}{l|l}
\hline Categorías & Códigos \\
\hline $\begin{array}{l}\text { Nuevos } \\
\text { conocimientos }\end{array}$ & $\begin{array}{l}\text { Abordar más temas, adquirir conocimien- } \\
\text { to, conocer nuevas situaciones, cualificar } \\
\text { cuidado, enseñanza, mejorar conocimiento, } \\
\text { conocimientos variados, saber cómo actuar. }\end{array}$ \\
\hline $\begin{array}{l}\text { Interacción } \\
\text { con otros }\end{array}$ & $\begin{array}{l}\text { Calor Humano, compartir con los compa- } \\
\text { ñeros, compartir experiencias, conocer } \\
\text { personas, empatía, integración con otros, } \\
\text { interacción con otros. }\end{array}$ \\
\hline Descansar & $\begin{array}{l}\text { Apoyo mutuo, ser escuchado, ser tenido } \\
\text { en cuenta, distribuir tareas, involucrar al } \\
\text { paciente, involucrar a la familia, escuchar. }\end{array}$ \\
\hline Bienestar & $\begin{array}{l}\text { Disminución carga emocional, distracción, } \\
\text { expresar sentimientos, autoconocimiento, } \\
\text { identificarse con otros. }\end{array}$ \\
\hline $\begin{array}{l}\text { Nueva } \\
\text { perspectiva }\end{array}$ & $\begin{array}{l}\text { Ser constructivo, fortalecerse, mejorar } \\
\text { autoestima, comprometerse con el autocui- } \\
\text { dado, mejorar estilo de vida, valorarse. }\end{array}$ \\
\hline $\begin{array}{l}\text { Oportunidad de } \\
\text { mejorar }\end{array}$ & $\begin{array}{l}\text { Comprender el rol, oportunidad de cambio, } \\
\text { organizar el rol, crecimiento personal, } \\
\text { valorar a las personas. }\end{array}$ \\
\hline torrenocimiento, visibilidad del cuidador.
\end{tabular}

Fuente: Elaboración propia datos del estudio 2015.

A continuación se describirán las categorías:

\section{Nuevos conocimientos}

Participar en el programa permite a los cuidadores adquirir conocimientos nuevos, los cuales se constituyen en una herramienta para cualificar el cuidado que brindan. Los conocimientos que adquieren son variados, pues engloban la complejidad del cuidado no solo en el ámbito instrumental, sino en la dimensión emocional, espiritual y social. Lo conocimientos nuevos se adquieren no solo en el plano cognitivo, sino en el comportamental, pues las situaciones de cuidado compartidas por otros cuidadores son un escenario propicio para ponerse en situaciones hipotéticas y saber cómo actuar ante ellas... "Se aprenden cosas que uno no sabía", "Nos ayudaron a reconocer nuestra fortalezas a conocernos a nosotros mismos", "hici- 
mos una integración para conocernos nosotros mismos", "Aprendí de lo que les pasa a los otros cuidadores, pasa sabe qué hacer ante las diferentes situaciones".

\section{Interacción con otros}

En el programa, los cuidadores tienen la posibilidad de interactuar con otros que como ellos han vivido la experiencia de cuidar a una persona en terapia de diálisis peritoneal. Esta interacción se caracteriza por el calor humano, la integración y el compartir experiencias que llevan a los cuidadores a crear un vínculo de empatía: "La afinidad con los demás cuidadores nos permitió compartir experiencias", "Estuvimos en un ambiente de compañerismo donde conocimos nuevas personas y nos integramos como cuidadores". Compartir las experiencias de cuidado con nuevas personas, se convierte en un pilar importante para sobrellevar su tarea de cuidador.

\section{Apoyo}

El apoyo es fortalecido en dos escenarios: entre los cuidadores del programa y en el entorno de provisión de cuidados.

El apoyo entre los cuidadores se da gracias al vínculo empático que emerge entre ellos. Este tipo de apoyo es favorecido por el ambiente de escucha que se vive dentro del programa, pues para los cuidadores el hecho de que alguien compasivo e interesado escuche su experiencia con atención, los hace sentir importantes y apoyados, ellos sienten que no están solos en el proceso y que otros como ellos están dispuestos a darles apoyo.

Frente al entorno de provisión de cuidados, es decir, en donde ellos ejercen su rol, los cuidadores reflexionan acerca de que es tan importante ser escuchado como también escuchar. En esa actitud de dialogicidad, se abren a escuchar a su receptor de cuidados y a su familia. Como resultado del proceso de reflexión, en donde se exalta la importancia de la comunicación, el cuidador empieza a involucrar a diferentes personas cercanas en su labor facilitándole la distribución de tareas de cuidado (es allí en donde materializan los apoyos). El cuidador reconoce que requiere ayuda y desarrolla la habilidad de identificar y acceder a sus redes de apoyo.

"Mis compañeros cuidadores me escuchan y me apoyan emocionalmente". "Aprendí el valor de la comunicación con mi paciente y con el resto de miembro de mi familia, con el fin de concretar los apoyos que necesito". "Entiendo que cuento con el apoyo de la institución".

\section{Descansar}

El programa "Cuidando a los Cuidadores@ versión institucional", ha sido descrito por los cuidadores como un escenario de descanso. En él, los cuidadores pueden expresar sus sentimientos sin temor a ser juzgados. Encuentran que otros como ellos viven situaciones de cuidado que agotan, abren espacio al autoconocimiento, encontrando que son seres humanos con grandes virtudes, pero también con limitaciones. Situación por la cual cansarse es una condición legitima en su rol como cuidador... "Pude expresar con sinceridad mi propia experiencia en lo relacionado con el cuidado del paciente". "Reaccioné y ahora entiendo que soy una persona que siente, igual que mi paciente". "Aprendí de los inconvenientes de los demás y ahora entiendo que no estoy sola en el proceso". En el desarrollo de los talleres logran distraerse y salir de la cotidianeidad del cuidado; esto les permite descansar.

\section{Bienestar}

Participar en el programa incita a los cuidadores trabajar por su propio bienestar. Los cuidadores expresan no haber reflexionado sobre este aspecto, pues todos sus esfuerzos se habían enfocado en el bienestar de su receptor de cuidados.

Los cuidadores reflexionan sobre la importancia de valorar su labor, fortalecerse en su rol, comprometerse con su autocuidado, mejorar sus estilos de vida y autoestima; lo anterior con el fin de maximizar su propio bienestar: "Ahora comprendo que debo retomar mi vida, pensar en mi futuro, valorarme". "Entiendo el significado y el valor que se le ha dado a mi trabajo como cuidador". "Reconocí cuanto valgo yo, que tengo muchas cualidades y valores y que debo velar por mi bien".

\section{Oportunidad de mejorar}

La continua reflexión sobre el rol de cuidador que se da en el programa promueve en los cuidadores una comprensión de la complejidad que implica el cuidar a una persona en diálisis peritoneal. Esta comprensión hace que el cuidador organice lo pertinente para ejercer su rol, cambiando en su forma de ver el valor de las personas empezando a ver el cuidado como una oportunidad de cambio que le hace crecer como persona. El cuidador comprende que no todo lo relacionado con el cuidado tiene consecuencias negativas, sino que por el contrario la determinación con que el cuidador asuma su rol puede transformar la experien- 
cia en algo muy positivo... "Compartir con las demás cuidadoras tantas experiencias y reconocer algunas fallas propias". "Me enfoqué para mejorar yo, en mi conocimiento para crecer y ayudar de mejor manera". "Me sirvió para querer hacer cambios en mi vida sin dejar de ser responsable". El cuidador reconoce que al asumir esta tarea de cuidado, obtiene recompensas a nivel personal, que puede relacionar con su espiritualidad.

\section{Nueva perspectiva}

Los cuidadores se reconocen a sí mismos y el significado de su rol en su propia vida y en la de otros, en especial su receptor de cuidados. El ser visibles para sí mismos promueve su visibilidad ante los demás, ven el cuidado como una labor que va más allá de la asistencia en actividades instrumentales, afirman su compromiso y esto les permite identificar logros y ganancias en su rol como cuidadores. Todo esto los lleva a plantarse nuevos retos para el futuro: "Hizo que me trazara metas. Separar mis metas de las del paciente". "Aprendí a programar mi tiempo, como cuidarme para poder ayudar a mi paciente". "Mi misión es especial y debo realizarla con amor y buena voluntad, por lo tanto todo lo que haga debe ser encaminado a lograr ser una persona paciente en todos momentos de mi vida, pero también debo pensar en mí".

\section{Discusión}

Esta investigación confronta el perfil del cuidador de personas con enfermedad renal crónica en terapia de diálisis peritoneal con el perfil tradicional del cuidador de personas con enfermedad crónica, encontrando que son muy similares. Los cuidadores de personas en terapia de diálisis peritoneal son mayormente mujeres de escolaridad que oscila entre el bachillerato y la media técnica, con edades que corresponden a la etapa productiva, con una unión marital constituida por matrimonio o de hecho, con ocupación hogar, de estrato dos o tres, que cuida desde el momento del diagnóstico y que en su mayoría son únicos cuidadores. Situación comparable con otros estudios en cuidadores de personas con enfermedad crónica ${ }^{14,15,16,17}$.

La experiencia de participar en el programa "Cuidando a los Cuidadores ${ }^{\odot}$ versión institucional", se constituye en un proceso de transformación del cuidador familiar. Esta transformación también fue observada por Alvarado ${ }^{18}$, quien realizó una teoría fundamentada con cuidadores familiares de personas con enfermedad crónica que asistieron al programa en su versión original. En este estudio, se observa que la experiencia que viven los cuidadores familiares de personas en terapia de diálisis peritoneal al participar en el programa en la versión institucional, tiene hallazgos muy cercanos a algunos de los planteados por Alvarado en su estudio. Uno de ellos, el que Alvarado define como variable de exploración y contacto y en la cual se identifica el apoyo como percepción dentro de la experiencia. El otro, la variable comprensión y progreso, que describe el proceso de intercambio, comprensión y organización que vive el cuidador, muy similar a lo que en este estudio se observa en las categorías de nuevos conocimientos, interacción con otros, descanso y bienestar. Finalmente, la variable cambio y nuevos retos, en la que se muestra la trascendencia en la experiencia de cuidar a través de la reflexión y la identificación de las ganancias y retos del cuidado; muy cercana a las categorías descritas en este estudio y denominadas oportunidad de mejorar y nueva perspectiva.

Lo anterior, confirma lo descrito por Carreño y Chaparro ${ }^{19}$, quienes afirman que la habilidad de cuidado crece a lo largo de la experiencia de ser cuidador y responde a factores relacionados como son el soporte social, que en este caso correspondería a la participación en el Programa "Cuidando a los Cuidadores ${ }^{\odot}$ versión Institucional". Además, estas autoras describen que a medida que se da el soporte social, la habilidad de cuidado aumenta y la calidad de vida en el cuidador se transforma de manera positiva, hallazgo que es congruente con la categoría bienestar que emergió en este estudio.

Las categorías descritas en este estudio permiten afirmar de forma cualitativa que los cuidadores tienen un aumento de su habilidad de cuidado como resultado de su participación en el programa. Al comparar las categorías que emergieron con los atributos centrales del planteamiento de Nkhongho ${ }^{20}$, se podría poner en paralelo el concepto de conocimiento con las categorías de nuevos conocimientos y descansar; el concepto de valor con las categorías de interacción con otros, bienestar y apoyo y el concepto de paciencia con las categorías de oportunidad de mejorar y nueva perspectiva. Lo anterior podría contrastarse con el encontrado por Díaz y Rojas ${ }^{21}$, en su estudio experimental con cuidadores de personas con enfermedad crónica que participaron en el programa en su versión original, quienes evidenciaron un aumento en la dimensiones de conocimiento y paciencia. Lo anterior expone la necesidad de hacer comprobaciones de este hallazgo a través de estudios experimentales. 


\section{Conclusiones}

La experiencia del cuidador familiar de personas en terapia de diálisis peritoneal de participar en el programa "Cuidando a los Cuidadores versión institucional" $\odot$, se caracteriza por una trasformación que va desde el adquirir nuevos conocimientos hasta tener una nueva perspectiva en su labor como cuidador. Son categorías emergentes del análisis de los datos: Nuevos conocimientos, interacción con otros, apoyo, descansar, bienestar, oportunidad de mejorar y nueva perspectiva.

Se requiere de investigación cuantitativa que valide los hallazgos derivados de este estudio.

\section{Agradecimientos}

A los cuidadores que hicieron parte de este estudio. Al Programa para la Disminución de la Carga de la Enfermedad Crónica no Transmisible en Colombia, proyecto financiado por Colciencias.

\section{Conflictos de interés}

Las autoras declaran no tener conflictos de interés.

Recibido: 14 agosto 2015

Revisado: 20 agosto 2015

Modificado: 21 agosto 2015

Aceptado: 21 agosto 2015

\section{Bibliografía}

1. Chaves Karen, Duarte Andrés, Vesga Jasmín. Adaptación transcultural del cuestionario KDQOL SF 36 para evaluar calidad de vida en pacientes con enfermedad renal crónica en Colombia. Rev. Fac. Med. 2013; 21(2): 34-42.

2. Torres Zamudio C. Insuficiencia renal crónica. Rev. Med. Hered. 2003, 14(1): 1-4.

3. Periz Lola, Gruart Armagué Paqui, Sánchez Lia Tamar. Visión enfermera de las necesidades psicosociales de los cuidadores de personas en tratamiento con Diálisis Peritoneal. Rev Soc Esp Enferm Nefrol. 2007, 10(1): 47-52.

4. Teixidó J, Tarrats $L$, Arias N, Cosculluela A. Cuestionario de sobrecarga de cuidadores de pacientes de diálisis peritoneal. Nefrología. 2006; 26(1): 7483.

5. Alvarado Alejandra. Experiencia de cuidar a un paciente con enfermedad crónica después de recibir una capacitación. Sal Unin Barr (Col.). 2010, 26(2): 232-249.

6. Romero Elizabeth, Maccausland Yakky, Solórzano Lucy. El cuidador familiar del paciente renal y su calidad de vida, Cartagena (Colombia). Sal Unin Barr (Col.). 2014; 30(2): 146-157.

7. Pinto Afanador Natividad, Barrera Ortiz Lucy, Sánchez Herrera Beatriz. Reflexiones sobre el cuidado a partir del programa "Cuidando a los cuidadores"®. Aquichán 2005(1): 128-137.

8. Barrera Ortiz Lucy, Pinto Afanador Natividad, Sánchez Herrera Beatriz. "Cuidando a los Cuidadores": Un programa de apoyo a familiares de personas con enfermedad crónica. Index Enferm 2006,15(52-53): 54-58.

9. Consejo de Organizaciones Internacionales de las Ciencias Médicas (CIOMS), Organización Mundial de la Salud. Pautas éticas internacionales para la investigación biomédica en seres humanos. [Internet] [Consultado 09 de Abril 2015]. Disponible en http://www.ub.edu/rceue/archivos/Pautas_Eticas_ Internac.pdf.

10. Resolución No. 008430: Por la cual se establecen las normas científicas, técnicas y administrativas para la investigación en salud. Ministerio De Salud, República de Colombia 1993. [Internet] [Consultado 09 de Abril 2015]. Disponible en http://www. unisabana.edu.co/fileadmin/Documentos/Investigacion/comite_de_etica/Res_8430_1993_-_Salud. pdf.

11. Atlas.ti. Qualitative Data Analysis. .[Internet] [Consultado 09 de Abril 2015]. Disponible en http://atlasti.com/es/.

12. Gil T, Cano A. Introducción al análisis de datos en investigación cualitativa: concepto y características. Nure investigación. 2010 (44). [Internet] [Consultado 09 de Abril 2015]. Disponible en http://www.nureinvestigacion.es/0JS/index.php/ nure/article/viewFile/476/465. 
13. Fernández F. El análisis de contenido como ayuda metodológica para la investigación. Revista de Ciencias Sociales. 2002; 56: 35-53.

14. Carrillo G, Barrera L, Sánchez B, Carreño S, Chaparro L. Efecto del programa de habilidad de cuidado para cuidadores familiares de niños con cáncer. Revista Colombiana de Cancerología. 2014; 18(1): 10-18.

15. Rodríguez M, Carrasco M, García MM, Gutiérrez P, Jiménez, E, López LA. Cuidadores familiares de personas con enfermedad neurodegenerativa: perfil, aportaciones e impacto de cuidar. Revista Atención Primaria. 2000; 26(3):139-144.

16. Lara G, González A, Blanco L. Perfil del cuidador: sobrecarga y apoyo familiar e institucional del cuidador primario en el primer nivel de atención. $R e$ vista de Especialidades Médico- Quirúrgicas. 2008; 13 (4): 159-66.
17. Casanova $P$, Rodríguez $M$, Herrero M. Perfil social de los cuidadores familiares de pacientes dependientes ingresados en el Hospital General Universitario de Elche. Gerokomos. 2009; 20(4): 167-171.

18. Carreño Moreno SP, Chaparro Diaz L. Reconstruyendo el significado de calidad de vida de los cuidadores en el cuidado: una metasíntesis. Av en Enfermería. 2015;33(1):55-66.

19. Nkongho N. The Caring Ability Inventory. En: Strickland OL and Waltz CF.measurement of Nursing Outcomes: SelfCare and Coping. Vol. 4 Edition. New York: Springer Publishing Company; 1990. P. 3-16.

20. Díaz JC, Rojas M. Cuidando al cuidador: efectos de un programa educativo. Aquichan. 2009; 9(1):7392. 